\title{
Analysis of Kudoa septempunctata as a cause of foodborne illness and its associated differential diagnosis
}

\author{
Sung Uk Lee \\ Jeju Special Self-Governing Provincial Office, Jeju, Korea
}

\begin{abstract}
OBJECTIVES: Recently kudoa septempuctata in olive flounders is suggested as a cause of food poisoning, however whether $k u-$ doa septempuctata can affect human gastrointestinal systems is controversial and its pathogenecity remains unclear. In view of the field epidemiology, food poisonings caused by kudoa septempuctata should be distinguished from those caused by staphylococcus aureus and bacillus cereus.

METHODS: The statistics of food poisoning investigations published by Korea Centers for Disease Control and Prevention in 2013-2015 were reviewed. The characteristics of kudoa septempuctata food poisoning reported by Korea Centers for Disease Control and Prevention were reviewed. Information regarding clinical symptoms or epidemiology was extracted.

RESULTS: Total eleven kudoa septempuctata food poisoning cases were analyzed. Food poisonings caused by kudoa septempuctata, staphylococcus aureus and bacillus cereus have clinical and epidemiological similarities. Forty five percent of food poisoning outbreaks occurred in Korea was concluded as unknown. The food poisoning caused by staphylococcus aureus and bacillus cereus accounted for 4.5\% (50/1,092) of all food poisoning outbreaks in Korea between 2013 and 2015.
\end{abstract}

CONCLUSIONS: This study suggests the possibilities of misdiagnosis in the investigations of food poisoning by staphylococcus aureus and bacillus cereus with kudoa septempuctata.

KEY WORDS: Food parasitology, Myxozoa, Kudoa septempunctata, Staphylococcus aureus, Bacillus cereus, Korea

\section{INTRODUCTION}

Foodborne outbreaks caused by Kudoa septempunctata and the characteristics of these cases were reported by Korea Centers for Disease Control and Prevention (KCDC) in its annual surveillance report. In addition, KCDC suggests the need for a new nationwide

\section{Correspondence: Sung Uk Lee}

Jeju Special Self-Governing Provincial Office, 6 Munyeon-ro, Jeju 63122, Korea

E-mail: sulee86rad@gmail.com

Received: Mar 23, 2017 / Accepted: Mar 31, 2017 / Published: Mar 31, 2017

This article is available from: http://e-epih.org/

(C) This is an open-access article distributed under the terms of the Creative Commons Attribution License (http://creativecommons.org/licenses/by/4.0/) which permits unrestricted use, distribution, and reproduction in any medium, provided the original work is properly cited.

(C) 2017, Korean Society of Epidemiology policy to prevent the spread of $K$. septempunctata and consequent food poisoning [1]. The numerous myxosporean species of the genus Kudoa reported around the world are not pathogenic to humans [2]. However, K. septempunctata has recently been considered as a human pathogen since it was first identified in olive flounders. This parasite was identified as a causative agent of food poisoning by the Ministry of Health, Labour and Welfare in Japan in December 2012, and its pathogenesis was also studied in an experiment using 4 to 5 -day old mice [3,4]. However, other mice studies had conflicting results [5], and studies on humans have not been reported with regard to this new species. Based on these grounds, Chung et al. [6] recently suggested that epidemiologic causality between K. septempunctata and food poisoning lacks scientific validity.

Meanwhile, based on the epidemiological investigation data, the cases of K. septempunctata food poisoning are characterized by a short incubation period and mild gastrointestinal distress [4], 
which are similar to the epidemiologic and clinical features of Staphylococcus aureus and Bacillus cereus food poisoning. Therefore, a differential diagnosis of K. septempunctata and the aforementioned bacteria is critical in identifying the former as a new foodborne pathogen. In this study, cases of K. septempunctata outbreak were investigated and compared with those caused by $S$. aureus and $B$. cereus. Moreover, the causes of foodborne illnesses that occurred from 2013 to 2015 were also analyzed.

\section{MATERIALS AND METHODS}

K. septempunctata outbreaks that were reported in the 2015 Annual Infectious Disease Surveillance Report and its appendix were reviewed to determine the characteristics of $K$. septempunctata food poisoning [1].

The identified characteristics were then compared with those of S. aureus (Chapter 8) and B. cereus (Chapter 1) outbreaks, which were extracted from the book "Pathogens and Toxins in Food" [10]. Individual $K$. septempunctata cases described in the appendix were analyzed to determine epidemiological features and current trends in epidemiologic investigations. To identify the causes of foodborne diseases in Korea, the incidence rates of water and foodborne diseases were reviewed in the aforementioned report of KCDC from 2013 to 2015 [7-9]. Therefore, outbreaks with unknown causes and $S$. aureus and B. cereus outbreaks, each of which was presented as a percentage ratio to the total outbreaks, will be identified.

\section{RESULTS}

\section{Comparison of clinical and epidemiological characteristics of $K$. septempunctata and S. aureus and $B$. cereus cases}

$S$. aureus produces heat-resistant enterotoxins, and B. cereus forms heat-resistant spores. These products are considered as the main cause of food poisoning (Table 1) [10]. Although cooking can kill these causal pathogens, toxins and spores are not destroyed and can cause food poisoning. According to a study about K. septempunctata with respect to human intestinal cells, this parasite causes food poisoning when its sporoplasm invades the intestinal cells. Although S. aureus and B. cereus are common foodborne pathogens, the number of outbreaks caused by these bacteria is underestimated because the symptoms of mild food poisoning are not reported worldwide. In addition, these pathogens are difficult to detect through in vitro diagnostic tests during epidemiologic investigations $[11,12]$. The ratio of $K$. septempunctata outbreaks to total foodborne illness outbreaks has not been clearly identified yet. S. aureus and B. cereus actively grow at a high temperature (20$37^{\circ} \mathrm{C}$ ), causing a higher incidence of infections in summer than in winter. However, no incidence of K. septempunctata food poisoning in the months of June and July was reported, while the incidence was spread evenly across the other months of the year (5-15 cases per month), showing the highest incidence in May. The KCDC identified a possible association between this incidence pattern and changes in sea water temperature [1]. Nonetheless, Song et al. [2] stated that $K$. septempunctata is detected in olive flounders throughout the year without changes in June and July. Their finding confirms that the incidence of food poisoning is more likely related to the consumption of olive flounders, which significantly decreases in summer. With the mean incubation period of less than six hours, the three pathogens mainly caused diarrhea and vomiting, and all symptoms lasted for less than 24 hours, with similar characteristics. S. aureus colonizes the human skin and nasal mucous membranes, whereas $B$. cereus is widely distributed in the natural environment, such as soil. Although the life cycle of K. septempunctata is not completely known, it is a parasite commonly found in olive flounders [13]. S. aureus and B. cereus can cause food poising through a variety of ways, including the ingestion of contaminated meat and dairy products and undercooked rice. By far, K. septempunctata infection only occurred after the consumption of olive flounder.

Table 1. Comparison of clinical and epidemiological characteristics between K. septumpunctata, S. aureus, and B. cereus food poisonings

\begin{tabular}{|c|c|c|c|}
\hline & K. septumpunctata & S. aureus ${ }^{1}$ & B. cereus ${ }^{1}$ \\
\hline Pathogenesis & $\begin{array}{l}\text { Invasion of intestinal epithelium by } \\
\text { sporoplasm (in vitro) }\end{array}$ & Heat-resistant enterotoxin & Heat-resistant spore \\
\hline Proportion of food borne illness & Not assessed & $1-5 \%$, usually underestimated & $1-30 \%$, usually underestimated \\
\hline Seasonal variation & $\begin{array}{l}\text { Peak in May, but reduces in sum- } \\
\text { mer season }\end{array}$ & $\begin{array}{l}\text { May be more in warm-hot season } \\
\text { than cold, rapid growth at room } \\
\text { air }\end{array}$ & $\begin{array}{l}\text { May be more in warm-hot season } \\
\text { than cold, rapid growth at room } \\
\text { temperature }\end{array}$ \\
\hline Main clinical symptoms & Diarrhea, vomiting, abdominal pain & Diarrhea, vomiting, abdominal pain & Diarrhea, vomiting, abdominal pain \\
\hline Incubation periods (hr) & Average $2(1-15)$ & $0.5-8.0$ & $\begin{array}{l}\text { Vomiting: 1-6 } \\
\text { Diarrhea: 6-24 }\end{array}$ \\
\hline Duration and severity of illness & $\begin{array}{l}\text { Usually resolved within } 24 \mathrm{hr} \text {, self- } \\
\text { limiting }\end{array}$ & $\begin{array}{l}\text { Usually resolved within } 24 \mathrm{hr} \text {, self- } \\
\text { limiting }\end{array}$ & $\begin{array}{l}\text { Usually resolved within } 24 \mathrm{hr} \text {, self- } \\
\text { limiting }\end{array}$ \\
\hline Life cycle & Unknown & Human skin, nasal passage, hair & Soil \\
\hline Common source of infection & Intake of raw olive flounder & $\begin{array}{l}\text { Meat, poultry, egg and dairy prod- } \\
\text { uct, salads }\end{array}$ & Rice, meat, soup \\
\hline
\end{tabular}

${ }^{1}$ Characteristics of S. aureus and B. cereus referred from Juneja et al. Pathogens and toxins in foods: challenges and interventions. Washington, DC: ASM Press; 2010 [10]. 


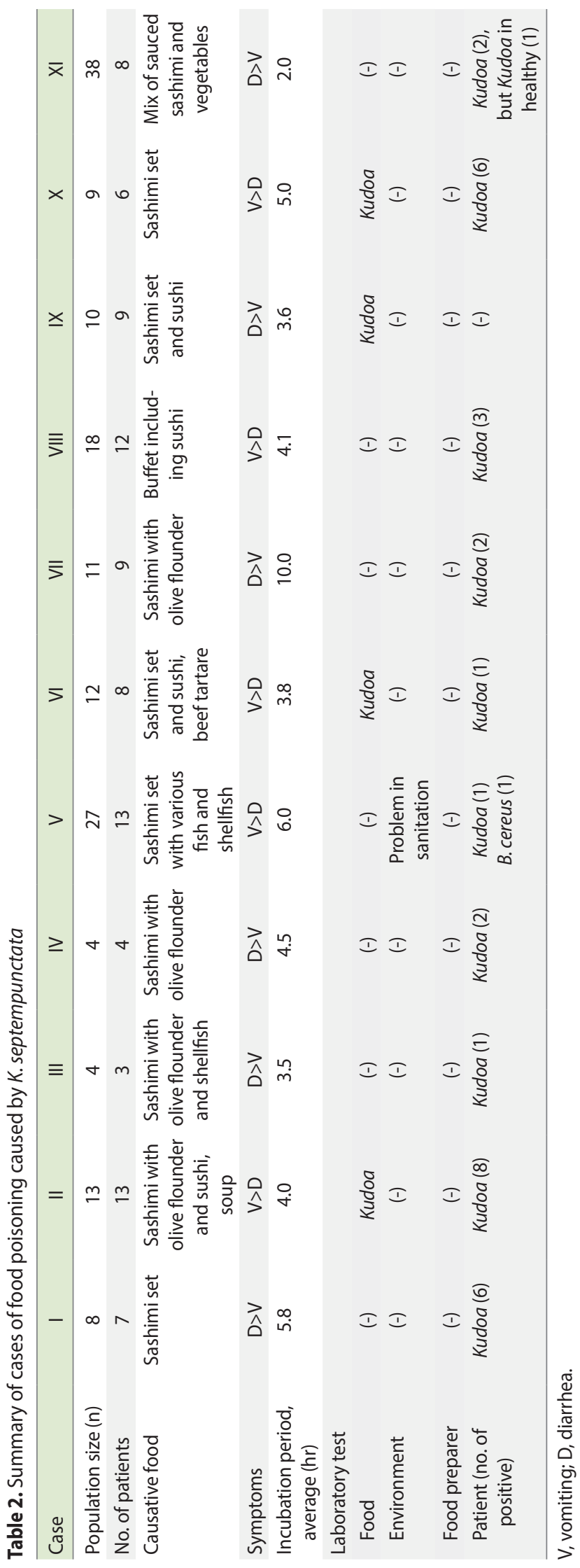

\section{Review of $K$. septempunctata outbreaks}

A total of 11 K. septempunctata outbreaks that occurred in 2015 are summarized (Table 2). Two out of 11 cases were caused by the ingestion of raw olive flounder, whereas the remaining nine cases were associated with the consumption of various fish, including olive flounder, shellfish, and sushi. Diarrhea was a more common symptom than vomiting in six outbreaks. However, vomiting was common in five outbreaks. The average incubation period ranged from 2 to 10 hours. Based on the results of laboratory tests, K. septempunctata was found in patients of 10 outbreaks and in official food samples in the remaining one outbreak (Outbreak 9) in which patients were not infected. In Outbreak 5, K. septempunctata was found along with B. cereus in samples of patients, and poor sanitation was observed. In Outbreak 11, K. septempunctata was detected in two patients and in one asymptomatic individual.

\section{Common causative agents of foodborne illness}

The causes of water and foodborne illnesses that occurred from 2013 to 2015 were analyzed (Table 3). The causative agent was unknown for 36 to $51 \%$ of the total outbreaks during the 3-year period, and the source of infection (food or drinking water) was unknown for 75 to $81 \%$ of the total outbreaks in 2013 and 2014 (2015 data not available). Norovirus, which is the most common gastrointestinal infection source in winter, was the leading cause of gastrointestinal infection in our review, accounting for between 16 and $19 \%$ of the total cases. Norovirus was followed by pathogenic intestinal bacteria (6-10\%)—Clostridium perfringens (3-11\%), and Salmonella spp. (2-7\%). A total of 26 S. aureus outbreaks occurred during the 3 -year period, accounting for $2.4 \%$ of the total foodborne illness outbreaks $(26 / 1,092)$, and B. cereus outbreaks constituted 2.2\% (24/1,092). In 2015 alone, K. septempunctata is the fifth most common cause of food poisoning with 11 outbreaks, accounting for $2.6 \%$ of the total outbreaks.

\section{DISCUSSION}

K. septempunctata has emerged as a foodborne pathogen that is associated with the consumption of olive flounder, and the national epidemiologic investigation report on foodborne illness recommends tests for K. septempunctata infection to those who eat olive flounder. Song et al. [2] reported that K. septempunctata was found in $4.9 \%$ of cultured olive flounder that were investigated. Given that olive flounder is a highly favored fish in Korea, a substantial amount of olive flounder parasitized with $K$. septempunctata is consumed. K. septempunctata infection is observed in cultured olive flounders that are distributed and remained intact, regardless of preparation methods, until it is eaten. The parasitic infection needs to be prevented during fish farming. As K. septempunctata has been discovered in olive flounder only, the epidemiologic investigation of food poisoning focused on detecting K. septempunctata DNA from clinical samples of patients who consumed olive flounders less than 24 hours before testing, regardless of the test results of food and environment samples. Thus, the test appro- 
Table 3. Annual trends in cause of food poisoning ${ }^{1}$

\begin{tabular}{|c|c|c|c|c|c|c|}
\hline Rank & 2015 & & 2014 & & 2013 & \\
\hline & Total & 422 & Total & 409 & Total & 261 \\
\hline & Unknown & $215(51)$ & Unknown & $186(45)$ & Unknown & $94(36)$ \\
\hline 1 & Norovirus & $79(19)$ & Norovirus & $48(12)$ & Norovirus & $42(16)$ \\
\hline 2 & E. coli & $26(6)$ & E. coli & $41(10)$ & C. perfringens & $30(11)$ \\
\hline 3 & Campylobacter & $22(5)$ & C. perfringens & $29(7)$ & E. coli & $19(7)$ \\
\hline 4 & C.perfringens & $14(3)$ & Salmonellosis & $28(7)$ & Salmonellosis & $12(5)$ \\
\hline 5 & Salmonellosis & $10(2)$ & Campylobacter & $23(6)$ & Shigella spp. & $8(3)$ \\
\hline 6 & S. aureus & $8(2)$ & S. aureus & $13(3)$ & B. cereus & $8(3)$ \\
\hline 7 & B. cereus & $6(1)$ & B. cereus & $10(2)$ & V. parahaemolyticus & $8(3)$ \\
\hline 8 & V. parahaemolyticus & $3(1)$ & V.parahaemolyticus & $6(1)$ & S. aureus & $5(2)$ \\
\hline
\end{tabular}

Values are presented as number (\%).

'Data from Korea Centers for Disease Control and Prevention. Epidemiological investigation of infectious diseases in Korea, annual report from 2013 to 2015 [7-9].

ach differs from other methods of foodborne illness investigation.

However, such an approach does not seem complete amid uncertainty over the pathogenic effects of K. septempunctata on food poisoning. Its pathogenicity to humans has been difficult to verify, and the animal-based studies revealed contradicting results, as discussed by Chung et al. [6]. The results of the pathogenic identification method that focused on K. septempunctata in the clinical samples of patients also contradict the findings in the study conducted by Ahn et al. [14] where K. septempunctata DNA was detected in mice without gastrointestinal symptoms. Therefore, based on these considerations, $K$. septempunctata may exist in fecal samples of patients who consumed olive flounders infected with the parasite, regardless of the development of food poisoning. As mentioned in Results, K. septempunctata was detected in a healthy individual in the control group in one out of the 11 outbreaks. The examination for the presence of K. septempunctata DNA in patients does not confirm the parasitic contribution to the onset of food poisoning.

Then, why does food poisoning occur after the consumption of olive flounder infected with K. septempunctata? Authors suggest the possibility that food poisoning caused by $S$. aureus or B. cereus is mistaken as K. septempunctata food poisoning. As discussed in Results, the cases of food poisoning caused by these three pathogens share similar epidemiological and clinical features, except that $K$. septempunctata is associated with the consumption of raw olive flounder. As mentioned in Results, S. aureus and B. cereus are the most common cause of food poisoning. However, each of these bacteria accounted for approximately $2 \%$ of the total foodborne disease outbreaks that occurred during the 3-year period. In 2015, the outbreaks of $S$. aureus and B. cereus food poisoning were lower than those of $K$. septempunctata food poisoning. Overall, the cause was unknown for half of all outbreaks, suggesting the possibility that bacterial food poisoning was not properly verified in numerous cases and that the actual outbreaks of these two bacteria were higher than that reported. Moreover, some $S$. aureus and $B$. cereus outbreaks that were classified as unknown causes because of the above-mentioned reasons can be mistaken as K. sep- tempunctata outbreaks, given that similar outcomes were observed. Among the 11 outbreaks described in Results, one K. septempunctata case and one B. cereus case were found in Outbreak 5. If the pathogenicity of the former is considered unclear, Outbreak 5 is suggested as a $B$. cereus case.

However, $S$. aureus and B. cereus are not easily identified as the causative agents of food poisoning, when compared with other food poisoning pathogens. To verify the causal relationship between the two bacteria and food poisoning with epidemiological data, the growth of epidemiologically relevant food-borne bacteria or enterotoxins and the clinical features (a short incubation period and mild gastrointestinal distress) of foodborne intoxication are important. Even in cases where foodborne intoxication is suspected based on clinical features, the availability of official food samples and the conditions for stool culture are significantly low, making in vitro diagnosis possible in only limited cases. Therefore, most cases are classified as unknown causes [10]. In cases where the food that caused food poisoning is recooked and distributed, in vitro diagnostic tests were then difficult to perform because cooking kills causative agents and the heat-resistant enterotoxins and spores that cause food poisoning.

During epidemiologic investigations, the identification of causes of food poisoning outbreaks should be carried out in a discreet manner because the involved parties, such as food supplier and future public health policy, may be affected. To further recognize the pathogenic effect of K. septempunctata on food poisoning, consistent effort is needed to improve the identification rate of $S$. aureus and $B$. cereus food poisoning cases, and further studies on the pathogenesis of $K$. septempunctata should be conducted.

\section{CONFLICT OF INTEREST}

The author has no conflicts of interest to declare for this study.

\section{ORCID}

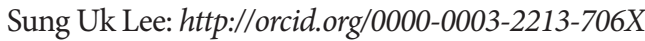




\section{REFERENCES}

1. Korea Centers for Disease Control and Prevention. Case reports of Kudoa food poisoning in 2015; 2016 [cited 2016 Dec 11]. Available from: http://cdc.go.kr/CDC/notice/CdcKrTogether0302.jsp? menuIds $=$ HOME001-MNU1154-MNU0005-MNU0088\&cid $=$ 71877 (Korean).

2. Song JY, Choi JH, Choi HS, Jung SH, Park MA. Monitoring of Kudoa septempunctata in cultured olive flounder and wild fish in Jeju Island during 2012. J Fish Pathol 2013;26:129-137 (Korean).

3. Kawai T, Sekizuka T, Yahata Y, Kuroda M, Kumeda Y, Iijima Y, et al. Identification of Kudoa septempunctata as the causative agent of novel food poisoning outbreaks in Japan by consumption of Paralichthys olivaceus in raw fish. Clin Infect Dis 2012;54:10461052.

4. Yoshiko Sugita-Konishi Y, Sato H, Ohnishi T. Novel foodborne disease associated with consumption of raw fish, olive flounder (Paralichthys olivaceus). Food Saf 2014;2:141-150.

5. Jang Y, Ahn M, Bang H, Kang B. Effects of Kudoa septempunctata genotype ST3 isolate from Korea on ddY suckling mice. Parasite 2016;23:18.

6. Chung YB, Bae JM. Is there evidence that Kudoa septempunctata can cause an outbreak of acute food poisoning? Epidemiol Health 2017;39:e2017004.

7. Korea Centers for Disease Control and Prevention. Epidemiological investigation of infectious diseases in Korea, annual report 2013; 2014 [cited 2014 Apr 21]. Available from: http://www.cdc.go.kr/ $\mathrm{CDC} /$ contents $/$ CdcKrContentLink.jsp? $\mathrm{fid}=43 \& \mathrm{cid}=26002 \&$ ctype
$=1$ (Korean).

8. Korea Centers for Disease Control and Prevention. Epidemiological investigation of infectious diseases in Korea, annual report 2014; 2016 [cited 2016 Apr 14]. Available from: http://www.cdc. go.kr/CDC/contents/CdcKrContentLink.jsp?fid $=43 \& \mathrm{cid}=67789$ \&ctype $=1$ (Korean).

9. Korea Centers for Disease Control and Prevention. Epidemiological investigation of infectious diseases in Korea, annual report 2015; 2016 [cited 2016 Nov 16]. Available from: http://www.cdc.go.kr/ CDC/contents/CdcKrContentLink.jsp?fid = 51\&cid = 71877\&ctype $=1$ (Korean).

10. Juneja VK, Sofos JN. Pathogens and toxins in foods: challenges and interventions. Washington, DC: ASM Press; 2010, p. 1-130.

11. Hennekinne JA, De Buyser ML, Dragacci S. Staphylococcus aureus and its food poisoning toxins: characterization and outbreak investigation. FEMS Microbiol Rev 2012;36:815-836.

12. Granum PE, Lund T. Bacillus cereus and its food poisoning toxins. FEMS Microbiol Lett 1997;157:223-228.

13. Kasai A, Li YC, Mafie E, Sato H. New host records of monacanthid fish for three Kudoa spp. (K. septempunctata, K. thyrsites, and K. shiomitsui) prevalent in the olive flounder (Paralichthys olivaceus), with the description of K. parathyrsites n. sp. from a black scraper (Thamnaconus modestus). Parasitol Res 2016;115: 2741-2755.

14. Ahn M, Woo H, Kang B, Jang Y, Shin T. Effect of oral administration of Kudoa septempunctata genotype ST3 in adult BALB/c mice. Parasite 2015;22:35. 